\title{
Calculating energy needs in critically ill patients: Sense or nonsense?
}

\author{
Herbert D. Spapen, Elisabeth De Waele, Sabrina Mattens, Marc Diltoer, \\ Viola Van Gorp, Patrick M. Honoré \\ Department of Intensive Care, University Hospital, Vrije Universiteit Brussel, Brussels, Belgium
}

\section{ABSTRACT}

High energy deficits due to underfeeding are frequently observed during critical illness and are associated with significant morbidity and mortality. Adequate determination of energy requirements is imperative for optimizing nutrition. For this goal, indirect calorimetry is considered to be the gold standard but it is expensive, time-consuming, and not readily available in many hospitals. As an alternative, most ICU physicians use bedside formulas to predict calorie needs. Some equations are obtained during resting metabolism in healthy humans and "corrected" by adding stress or injury factors. Others are derived from regression analysis in patients whereby various static and dynamic variables are identified and eventually adjusted for type of patient and/or disease. Few studies have evaluated the accuracy of predictive equations in critically ill patients. The largest prospective study to date identified the Penn State equation, including a modified version for obesity, as being the most accurate. Whether the systematic use of (a) particular formula(s) for estimating calorie needs may influence morbidity or outcome in ICU patients remains to be determined.

Key words: Critical illness, energy needs, indirect calorimetry, predictive equations, review

\section{INTRODUCTION}

Malnutrition is a persisting problem in intensive care patients worldwide. A negative energy balance, in particular, is consistently associated with significant organ dysfunction, ${ }^{[1]}$ enhanced infection risk $^{[2]}$ and worse outcome. ${ }^{[3]}$ Also, deleterious consequences of underfeeding are not easily measurable and may even become apparent after discharge from the intensive care unit (ICU).

Assessment of energy expenditure is a cornerstone of an adequate nutrition policy in the critically ill. However, whether energy expenditure in critically ill patients should be measured or estimated remains matter of debate. Consensus is that indirect calorimetry (IC) is the most accurate method to determine resting metabolic rate. ${ }^{[4]}$ However, IC is not always available. Measurements require trained personnel and are time-consuming. IC devices also are expensive and not all currently commercialized calorimeters produce comparable within-subject results. ${ }^{[5]}$ Patientrelated factors represent another potential bias. Indeed, many ICU conditions (e.g. ventilation at $\mathrm{FiO}_{2}$ levels exceeding $60 \%$, air leaks, high PEEP levels...) impede or prohibit IC use. ${ }^{[4,6]}$ Finally, many critically ill patients have an unstable metabolic course and may display significant variations of energy expenditure over time. This implies that an IC measurement at one time point may fail to appreciate the calorie need during a prolonged treatment period.

\section{Predictive equations as surrogate for indirect calorimetry}

From a multiple regression analysis of biometric variables, Arthur Harris and Francis Benedict constructed almost a century ago a landmark formula that predicted basal energy expenditure (BEE) in healthy male $[66.4730+(13.7516 \times$ weight $)+(5.0033 \times$ height $)-(6.7550 \times$ age $)]$ and female $[655.0955+(9.5634 \times$ weight $)+$ $(1.8496 \times$ height $)-(4.6756 \times$ age $)]$ subjects. ${ }^{[7]}$ In this Harris-Benedict equation (HBE), BEE represented energy expenditure 
occurring at complete rest after an overnight fast. In general, BEE is considered to be synonymous with resting energy expenditure (REE). However, it might be questioned whether this is also applicable in hospitalized patients.

In a review of 19 studies, including 1256 hospitalized subjects, REE measured with IC was compared with BEE estimated with the HBE. Patients with burns, head injuries, and fever who are known to be hypermetabolic were excluded. For all studies taken together, mean REE/BEE ratio was $113 \% \pm 11 \%$. The ratio was $117 \% \pm 3 \%$ in fed patients (11 studies) as compared to $105 \% \pm 4 \%$ in fasting patients (5 studies) $(P=0.047)$. Also, higher values (124 to $130 \%$ ) were observed in more severely ill (i.e., trauma and ICU patients) than in stable postoperative and cancer patients..$^{[8]}$ Thus, indiscriminate use of the "original" HBE may underestimate energy needs in a large proportion of hospitalized patients, and particularly in critically ill subjects. This led to the introduction of "corrected" HBEs. Basically, the calculated HBE was multiplied by correction factors adapting the REE to the level of stress induced by the underlying clinical condition or disease $\left(\times 1.3\right.$ per ${ }^{\circ} \mathrm{C}$ above $37^{\circ} \mathrm{C}$; $\times 1.2$ for minor surgery; $\times 1.35$ for major surgery and trauma; $\times 1.6$ for severe infection or sepsis). Also, an adjusted formula was proposed for obese patients.

Today, as many as 200 equations for calculating REE have been developed. Grossly, they can be divided in formulas based on "static" variables (i.e., gender, age, weight) only (e.g., Harris-Benedict, Fusco, Mifflin, ACCP recommendation,...) and formulas in which dynamic variables (i.e., body temperature, tidal and minute ventilation volume) reflecting the patient's metabolic state were added (e.g., Penn-State, Swinamer, Faisy,...). New formulas were also conceived to allow adaptation to pathology (e.g., IretonJones for trauma and burns), stress (e.g., the corrected HBE) or type of patient (e.g., obesity)..$^{\left[{ }^{[0]}\right.}$

\section{Value of predictive equations in the critically ill}

Few studies have validated the accuracy of calculated energy needs in critically ill patients. Kross et al. retrospectively compared five equations (HBE, Owen, Mifflin, IretonJones equation for obesity, and ACCP recommendation) with measured energy expenditure in 927 critically ill patients. ${ }^{[10]}$ None of the equations accurately matched measured REE, most of them underestimating energy needs. However, this study is not representative for a general ICU population, In fact, 4 of the 5 studied formulas comprised "static" variables only, $43 \%$ of the enrolled patients had a body mass index $>30 \mathrm{~kg} / \mathrm{m}^{2}$, and mean measured REE was very high $(2456 \pm 807 \mathrm{kcal} / \mathrm{d})$. The latter could be explained by the use of the MedGraphics CCM Express calorimeter in this study. This calorimeter was shown to produce $64 \%$ higher mean REE values as compared to the Deltatrac Metabolic Monitor which is the most extensively used and validated — though no longer produced — system for performing IC in an ICU setting. ${ }^{[1]}$

We conducted a retrospective observational study in 161 critically ill mechanically ventilated adult medico-surgical patients. ${ }^{[12]}$ REE was measured with the VmaxTM Encore 29 n calorimeter at $8 \pm 6$ days after ICU admission and compared with 10 equations commonly used by ICU physicians [Table 1]. All equations failed to achieve a clinical acceptable accordance with measured REE.

In 70 medical metabolically stable ventilated ICU patients, aged $61 \pm 18$ years, Faisy et al. identified weight, height, expired minute ventilation $(\mathrm{Vm})$ and body temperature (T) as independent variables for calculation of REE. The resulting formula $[(8 \times$ weight $)+(14 \times$ height $)+(32 \times \mathrm{Vm})$ $+(94 \times T)-4834]$ showed good correlation $\left(r^{2}=0.61\right)$ with IC and proved to be highly superior to the HBE, either corrected or not. ${ }^{[13]}$ The Faisy equation was subsequently validated prospectively in 45 mechanically ventilated patients of similar gender composition and age. Compared to the original study, patients were less severely ill (SAPS II score on day of IC monitoring $39 \pm 13 v$ s. $49 \pm 13$ ) and had less pneumonia ( $8 v$ s. 27). Again, the Faisy equation correlated well $\left(r^{2}=0.62\right)$ with measured REE and provided precise and unbiased REE estimations. In contrast, other simultaneously studied equations (Swinamer, Fusco, IretonJones, and (corrected) HBE) did not reach acceptable correlation and tended to over-or underestimate caloric needs. ${ }^{[14]}$

Frankenfield et al. conducted the largest prospective validation study to date comparing energy expenditure equations to IC measurements in mechanically ventilated medico-surgical and trauma patients. ${ }^{[15]}$ In this study, 202 patients were divided in four groups according to age and body mass index (BMI), with cut-off values for "young age" and "non-obesity" respectively $<60$ years and BMI $<30 \mathrm{~kg} / \mathrm{m}^{2}$. Accurate estimation of REE was defined as the percentage of estimates that fell within $10 \%$ above or below the measured value. Of 17 equations tested, including original, "stress-corrected" and weight-adjusted formulas, the Penn State equation (PSE, Table 2) provided the most accurate assessment of REE (ranging from $69 \%$ to $77 \%$ ), except in older overweight patients. ${ }^{[15]} \mathrm{A}$ modified equation for this patient segment was proposed by the same investigators ${ }^{[15]}$ and was later shown to have an accuracy rate of $74 \% .{ }^{[16]}$ Interestingly, the Faisy equation proved almost as accurate as the PSE in non-obese and obese patients younger than 60 (respectively $65 \%$ and $72 \%$ ) but dramatically underperformed in patients older than $60 .{ }^{[15]}$ This is somewhat unexpected given the much 
Table 1: Equations for calculating resting energy expenditure (kcal/day)

\begin{tabular}{|c|c|c|c|}
\hline \multirow[t]{2}{*}{ Harris Benedict 1919} & \multicolumn{3}{|c|}{ (1) $66.4730+(13.7516 \times W)+(5.0033 \times H)-(6.7550 \times A)$} \\
\hline & \multicolumn{3}{|c|}{ P: $655.0955+(9.5634 \times W)+(1.8496 \times H)-(4.6756 \times A)$} \\
\hline \multirow[t]{2}{*}{ Harris Benedict 1984} & \multicolumn{3}{|c|}{ J: $88.362+(13.397 \times W)+(4.799 \times H)-(5.677 \times A)$} \\
\hline & \multicolumn{3}{|l|}{ q: $447.593+(9.247 \times W)+(3.098 \times H)-(4.33 \times A)$} \\
\hline Faisy & \multicolumn{3}{|l|}{$(8 \times W)+(14 \times H)+(32 \times V m)+(94 \times T)-4834$} \\
\hline Ireton-Jones 1992 & \multicolumn{3}{|c|}{$1925-(10 \times A)+(5 \times W)+(281$ if $\pi)+(292$ if trauma present $)+(851$ if burns present $)$} \\
\hline Ireton-Jones 1997 & \multicolumn{3}{|c|}{$1784-(11 \times A)+(5 \times W)+(244$ if $\pi)+(239$ if trauma present $)+(840$ if burns present $)$} \\
\hline Penn State 1998 & \multicolumn{3}{|c|}{$(1.1 \times$ value of $\mathrm{HBE})+\left(140 \times \mathrm{T}_{\max }\right)+(32 \times \mathrm{VE})-5340$} \\
\hline Penn State 2003 & \multicolumn{3}{|c|}{$(0.85 \times$ value of $\mathrm{HBE})+\left(175 \times \mathrm{T}_{\text {max }}\right)+(33 \times \mathrm{VE})-6433$} \\
\hline Swinamer & \multicolumn{3}{|c|}{$(945 \times B S A)-(6.4 \times A)+(108 \times T)+(24.2 \times R R)+(817 \times V t)-4349$} \\
\hline ACCP recommendation & $\begin{array}{l}25 \times W \\
\text { - if BMI } 16-25 \mathrm{~kg} / \mathrm{m}^{2} \text {, use usual body } W \\
\text { - if } \mathrm{BMI}>25 \mathrm{~kg} / \mathrm{m}^{2} \text {, use ideal body } W \\
\text { - if } \mathrm{BMI}<16 \mathrm{~kg} / \mathrm{m}^{2} \text { use existing body } W \text { fo }\end{array}$ & first $7-10 d$, then & IBW \\
\hline \multirow[t]{8}{*}{ ESICM '98 statement } & Caloric target $=$ caloric need $\times$ corrected IBW & Corrected IBW & \\
\hline & Formula for calculating IBW & If $\mathrm{BMI}<18.5$ & $($ IBW + actual body $W) / 2$ \\
\hline & J: $50+[0.91 \times(\mathrm{H}-152.4)]$ & If BMI 18.5-27 & IBW \\
\hline & $q: 45.5+[0.91 \times(\mathrm{H}-152.4)]$ & If $\mathrm{BMI}>27$ & $\mathrm{IBW} \times 1.2$ \\
\hline & \multicolumn{3}{|c|}{ Caloric need (kcal/kg/day) } \\
\hline & & q & $\hat{0}$ \\
\hline & & $A \leq 60$ years 30 & 36 \\
\hline & & $A>60$ years 24 & 30 \\
\hline
\end{tabular}

ACCP: American College of Chest Physicians, ESICM: European Society of Intensive Care Medicine, $O^{\lambda}$ : Male, + : Female, W: Weight (kg), H: Height (cm), A: Age (years), Vm: Minute ventilation (L/min), T: Body temperature $\left({ }^{\circ} \mathrm{C}\right), \mathrm{BSA}$ : Body surface area $\left(\mathrm{m}^{2}\right)$, HBE: Harris Benedict equation, Tmax: Maximum body temperature in the past $24 \mathrm{~h}\left({ }^{\circ} \mathrm{C}\right), \mathrm{RR}$ : Respiratory rate (breaths/min), IBW: Ideal body weight $(\mathrm{kg}), \mathrm{BMI}$ : Body mass index $\left(\mathrm{kg} / \mathrm{m}^{2}\right)$, VE: Expired minute volume (L/min), Vt: Tidal volume (L)

Table 2: Penn state equations

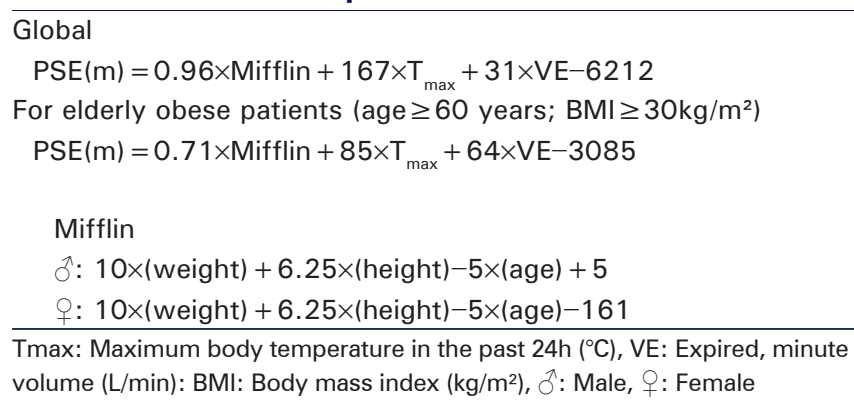

better results obtained in this population (with a mean age of 61 years!) in the original studies. ${ }^{[13,14]}$ The PSEs also predicted REE within $5 \%$ of the value measured by IC over a one-week time period. ${ }^{[17]}$ This performance correlates with a practice of making one measurement and extrapolating it over 1 week.

\section{CONCLUSIONS}

Static equations, in particular when uncorrected for underestimation of energy needs (e.g., HBE, Mifflin, ACCP recommendation) should not be used in the critical care setting. Equations developed for specific patient populations (e.g., Ireton-Jones for burn and trauma) are inaccurate for use in a general medico-surgical critically ill population. $\operatorname{PSE}(m)=[0.96 \times$ Mifflin $+167 \times$ Tmax + $31 \times V m-6212]$ is the most accurate equation overall and across patient subgroups. A variant PSE for older obese patients has been proposed and validated. The Faisy equation performs as well as the PSE (m) in young subjects ( $<60$ years) but in older patients it is biased towards overestimation and thus inaccurate. Despite better insight and considerable progress in the field, further research into more accurate bedside estimation of energy needs in critically ill patients, particularly regarding outcome, remains imperative.

\section{REFERENCES}

1. Dvir D, Cohen J, Singer P. Computerized energy balance and complications in critically ill patients: An observational study. Clin Nutr 2006;25:37-44.

2. Rubinson L, Diette GB, Song X, Brower RG, Krishnan JA. Low caloric intake is associated with nosocomial bloodstream infections in patients in the medical intensive care unit. Crit Care Med 2004;32:350-7.

3. Faisy C, Lerolle N, Dachraoui F, Savard JF, Abboud I, Tadie JM, et al. Impact of energy deficit calculated by a predictive method on outcome in medical patients requiring prolonged acute mechanical ventilation. Br J Nutr 2009;101:1079-87.

4. Cooney RN, Frankenfield DC. Determining energy needs in critically ill patients: Equations or indirect calorimeters. Curr Opin Crit Care 2012;18:174-7.

5. Cooper JA, Watras AC, O'Brien MJ, Luke A, Dobratz JR, Eartman CP, et al. Assessing validity and reliability of resting metabolic rate in six gas analysis systems. J Am Diet Assoc 2009;109:128-32.

6. Lev S, Cohen J, Singer P. Indirect calorimetry measurements in the ventilated critically ill patient: Facts and controversies-The heat is on. Crit Care Clin 2010;26;e1-9.

7. Harris JA, Benedict FG. A biometric study of human basal metabolism. Proc Natl Acad Sci U S A 1918;4:370-3.

8. Miles JM. Energy expenditure in hospitalized patients: Implications for nutritional support. Mayo Clin Proc 2006;81:809-16. 
9. Walker RN, Heuberger RA. Predictive equations for energy needs for the critically ill. Respir Care 2009;54:509-21.

10. Kross EK, Sena M, Schmidt K, Stapleton RD. A comparison of predictive equations of energy expenditure in critically ill patients. J Crit Care 2012;27:321:e5-12.

11. Sundström M, Tjäder I, Rooyackers $\mathrm{O}$, Wernerman J. Indirect calorimetry in mechanically ventilated patients. A systematic comparison of three instruments. Clin Nutr 2013;32:118-21.

12. De Waele E, Opsomer T, Mattens S, Diltoer M, Honore PM, Spapen $\mathrm{H}$, et al. A critical appraisal of formulas calculating resting energy expenditure in critically ill adult patients. Abstract 0740, presented at the $26^{\text {th }}$ ESICM Annual Congress, Paris 2013.

13. Faisy C, Guerot E, Diehl JL, Labrousse J, Fagon JY. Assessment of resting energy expenditure in mechanically ventilated patients. Am J Clin Nutr 2003;78:241-9.

14. Savard JF, Faisy C, Lerolle N, Guerot E, Diehl JL, Fagon JY. Validation of a predictive method for an accurate assessment of resting energy expenditure in medical mechanically ventilated patients. Crit Care Med 2008;36:1175-83.

15. Frankenfield DC, Coleman A, Alam S, Cooney RN. Analysis of estimation methods for resting metabolic rate in critically ill adults. JPEN J Parenter Enteral Nutr 2009;33:27-36.

16. Frankenfield D. Validation of an equation for resting metabolic rate in older obese, critically ill patients. JPEN J Parenter Enteral Nutr 2011;35:264-9.

17. Frankenfield DC, Ashcraft CM, Galvan DA. Longitudinal prediction of metabolic rate in critically ill patients. JPEN J Parenter Enteral Nutr 2012;36:700-12

How to cite this article: Spapen HD, De Waele E, Mattens S, Diltoer M, Gorp VV, Honoré PM. Calculating energy needs in critically ill patients: Sense or nonsense?. J Transl Intern Med 2014;2:150-3.

Source of Support: NIL. Conflict of Interest: None declared 